\title{
The Impact of Rapid Population Growth on Economic Growth: Evidence From Ethiopia
}

\author{
Tekilu Tadesse $^{1^{*}} \quad$ Deresse Dalango $^{2}$ \\ 1.Department of Economics, Jimma University, Ethiopia \\ 2.Department of Economics, Wolaita Sodo University, Ethiopia
}

\begin{abstract}
Rapid population growth is increasing from time to time as a result of high fertility and migration rate. This has a greater impact on the quality life of the society, in case of increasing number of unemployed peoples, lack of job opportunity, decrease in land share, infrastructure and so on. The objective of this study aimed to examine the impact of rapid population on economic growth of Ethiopia country by employing Autoregressive distributed lag model for the time period spanning from 1975 to 2019. The variables used in model were, population, consumer price index, gross investment proxied by gross capital formation and trade openness as explanatory variables and RGDP proxy for economic growth used as dependent variable. To check stationarity properties of the data augmented dickey fuller unit root test was used and the result indicates all the variables are non-stationary at level and become stationary at first difference. Regarding cointegration test, ARDL bound test used to test the existence of long-run association among the variables and the result confirmed that there is long run relationship among RGDP and explanatory variables. The empirical result obtained from ARDL Model revealed that gross capital formation and consumer price index have found to be positive and statistical significant impact on RGDP in both short run and long run where as our variable of interest meaning population growth is negatively affecting real GDP in the short run but, in the long run it is found to be positive and statistical significantly affecting economic growth.
\end{abstract}

Keywords: population growth, economic growth, ARDL, Bound test, Ethiopia

DOI: $10.7176 / \mathrm{JESD} / 11-15-02$

Publication date:August $31^{\text {st }} 2020$

\section{INTRODUTION}

When people first started to cultivate food through agriculture some 12,000 years ago, the estimated world population was no more than 5 million. One year before the beginning of the industrial revolution around 1750, the world population was around 728 million people, less than three-quarters of the total number living in India today. However, only the next 200 years (1750-1950), an additional 1.7 billion people were added to the planet's numbers. Astoundingly, in just four decades thereafter (1950-1990), the earth's human population more than doubled again, bringing the total figure to around 5.3 billion. In 2013, the world's population reached about 7.2 billion people (Todaro, Michael P., 1994). The overwhelming majority of that population will inhabit the developing world. Such rapid growth in population result decline in the per capital land holds of households that led fall in food production and rises poverty cycle in the societies (EH Tartiyus, 2009).

Ethiopia is one of the under developed country and characterized by rapid population growth which is not balanced with economic growth of the county. Its estimated population of 18 million in 1950 ranked it $25^{\text {th }}$ in the 
world which tinkle to 60 million in 1998 ranked $20^{\text {th }}$ and this number expected to be 169 million in 2050 were ranked country $9^{\text {th }}$ most populated in the world and $2^{\text {nd }}$ in Africa following Nigeria(UN, 1998). The Ethiopian annual growth rate was $2.4 \%$ with the doubling time of population is about 24 year. Such rapid population growth strains the country's economic performance since it influence the per capita income.

In the situation where population size is grow fast, the demand for food supply, health protection; education facilities and job opportunity of labor force are increase simultaneously. These faster demands for social service, PCI, natural resource, basic need and quality of living standard are beyond the capacity of households and economic capacity that leads to under growth of economy. In Ethiopia rapid population growth bring to a reduction in per capital income, social service provision, unemployment, dependency ratio, natural resource and environment degradation, job opportunity, basic need self-sufficient provision of good and service and size of land available for farming and housing. In Ethiopia the land holding size is the main constraint for achieving food security, since 1970s it was facing a recurrent famine (EEA, 2000). According to UN (2002), Ethiopia was facing very large emergence aid, which the projection of 10-15 million people, requiring food assistance. The implication is that the country unable to provide the growing population with basic necessity.

Based on the prior theoretical and empirical point the relationship between population growth and economic growth can be negative, positive or neutral depending on the countries level of economic performance and demographic structure. Theoretically the Malthusian class considered unprotected population growth as threat for economic growth while neo-Malthusian argued that population as the opportunity to economy since the level of technology is enhanced by population (Simon Julian 1979, Robert Malthus, 1798).

Most of the empirical finding reveals the negative relation between population growth and economic growth (Robert Barro, 1991; Dao, 2012; Afzal et.al, 2009; Razin and Sadka, 1995). The enhanced neoclassical growth model of Mankiw, Romer, and Weil (1992:407-437) also shows that higher population growth lowers income per capita because the available capital must be spread more thinly over the population of workers. In contrary, Birdsall, Kelley, and Sinding (2003) found a positive relationship between population growth and per capita output growth among DCs. According to Bloom and Freeman (1986), the economic growth is independent of population growth. There was no evidence either population growth's positively or negatively influencing the economy. Likewise, the findings of Barlow (1994) was more mixed, indicating that whereas past fertility rates are positively related to economic growth, present population growth is negatively related to economic growth. The work of Goodfriend and McDermott (1995) show that population growth may increase or decrease GNP per capita, depending on the relative size of the preindustrial and market sectors. Thus, there was no cross cutting conclusion about the link between population growth and economic growth. Yet, empirical investigation on impact of population growth on economic growth in case of Ethiopia is rare. This calls further empirical examination to restrain the gap.

This study would confine the methodological gap that persists in prior research in interest area. Most of the former research have applied ordinary least squares and conventional panel data analysis (shown in literature review part). However, the Autoregressive Distributive Lag (ARDL) model has a superior advantage over these above mentioned methods. Hence, this study fills the gap by applying ARDL model to perform the short- and long-run link between population growth and economic growth in Ethiopia covering from the year 1975 to 2019 . 


\section{Literature Review}

Population is the productive live and health of individual, couples, community and all the people in a country. Population is a group of people living in a definite geographic area. The world most growth center of population is the LDCs. In the world, LDCs have very high birthrates, while developed country has birth rate below replacement rate. Population growth rate in LDCs is $2 \%$ per annual, compared to $1.1 \%$ in middle income countries and $0.7 \%$ per annual in DCs. Natural resource is naturally limited but being and need and wants are not limited. In LDCs, due to high birth rate children under age 15 are $32 \%$ of total population, while $17 \%$ in DCs, this refers dependence burden on active labor force to support financially more children and older (UN, 1998). The main question here is do population growth an obstacle to economic development or opportunity?

There are two influential arguments about the relation between population growth and economic growth. The first one was the Malthusian population trap, which put forward a theory of the relationship between population growth and economic development that is influential today. Malthus's theory was that population, which increased geometrically - 1, 2, 4, 8, 16, 32, and so on - outstripped food supply, which grew arithmetically: 1, 2, 3, 4, 5, 6 . Accordingly, due to diminishing returns to the fixed factor, land, food supplies could expand only at a roughly arithmetic rate. In fact, as each member of the population would have less land to work, his or her marginal contribution to food production would actually start to decline. Because the growth in food supplies could not keep pace with the burgeoning population, per capita incomes (defined in an agrarian society simply as per capita food production) would have a tendency to fall so low as to lead to a stable population existing barely at or slightly above the subsistence level. For Malthus, a clergyman as well as an economist, the only check to population growth would be wars, epidemics, infanticide, abortion, and sexual perversion, unless people practiced moral restraint, that is, later marriages and abstention. Even then he believed living standards would remain at a subsistence level in the long run (Robert Malthus, 1798). Hence, this theory postulates the negative impact of population growth on economy.

However, due to his failure to take account of the capital accumulation and technical progress that would overcome diminishing returns on land, the Malthusian disparate with Neo-Malthus theory of population. Some economists' optimism about technological change makes them not only believe that output will continue to grow more rapidly than population but also that population growth stimulates per capita output growth. Julian Simon (1979) argues that the level of technology is enhanced by population. More people increase the stock of knowledge through additional learning gains compounded by the quickening effect of greater competition and total demand spurring "necessity as the mother for invention." Division of labor and economies of large scale production increase as markets expand. In short, as population size rises, both the supply of, and demand for, inventions increase, thereby increasing productivity and economic growth. From aforementioned theory, one can understand about conflicting arguments about the positive and negative consequences of population growth on economic growth. Population growth can positively influence economy if the additional population produce more technology and innovation which can increase factor productivity.

In most developing countries rapid population growth has various consequences on economic growth. According to UN, in LDCs $80 \%$ of population engaged in agriculture production, However, land holding diminishing that decrease production of agriculture result in short age of food securities. As population rises the demand for natural resource and social service increase and capital per worker ratio decrease lowering standard of 
living. Population have a major barrier to alleviate poverty cycle, inequality and under growth of economic absorbing capacities of economy increases unemployment and migration of labor force. Population growth dampens economic growth and social transformation through capital shadowing effect that is reduction in capital per worker ratio, age dependence of young resulting in high consumption of food production, depleting saving and investment activity in the country (EEA, 2000).

Rapid population growth in developing countries especially in Ethiopia in the context of low technological advancement is exerting heavy pressure on natural resource and environment condition. The rising demand for food supply result from rapid population growth had led to the expansion of cultivation in to land, generally, unsuitable for crop production and animal husbandry. The traditional means of exploiting natural resource have to be environmentally harmed full and economically unproductive. Ethiopians cultivating system is mostly by traditional which leads to shortening of fallow periods and crop rotation that helped maintain soil fertility. This traditional means of cultivation have led to increase rate of erosion, but decrease agricultural production. High demand for new farm lands, for age for livestock and fuel wood and charcoal for cooking have contributed significantly to the massive reduction and destruction of forest and woodland resources (Befekadu.D and Birhanu, $\mathrm{N}, 2000)$.

The empirical analysis by Robert Barro (1991), shows that the increased resources devoted to child rearing instead of production contribute to the negative relationship between population growth rate and income per capita. He used cross-country empirical study of virtually 100 countries. According to the finding population growth is likely to hamper growth in the first few decades of the $21^{\text {st }}$ century in Africa and parts of South Asia unless economic, population, and environmental policies adjusted. In contrary, Birdsall, Kelley, and Sinding (2003) found a positive relationship between population growth and per capita output growth among DCs.

Moreover, Klasen and Lawson (2007) identified a positive impact of population growth on economic growth. They conducted the link between population, per capita growth and poverty in Uganda using both cross-section and panel data. Yet, Dao (2012) found the negative impact of population growth on output growth. This study was conduct in developing Countries by using the least-squares estimation technique in a multivariate linear regression. Afzal et.al (2009) also investigated the link between population growth and economic growth in Pakistan by employing simple linear regression model. The result show that population growth negatively impulse economic growth. From aforesaid empirical and theoretical literature one can comprehend that, the relation between population growth and economic growth might be negative or positive depending on countries economic status and demographic structure.

\section{METHODOLOGY OF THE STUDY}

\subsection{Types of data and source of data}

Regarding data type, the study used secondary time series data for about 45 years obtained from internal and external sources. The selection of this sample size is made based on the availability of data for each of the variable included in the model for the entire time horizon while its sufficiency is taken into consideration as well. The major sources of data for the problem under investigation were Ministry of Finance and Economic Cooperation (MoFEC), publications of National Bank of Ethiopia (NBE), Central Statistics Authority (CSA) of Ethiopia, Ministry of Education and Ethiopian Revenue and customs authority (ERCA). In addition to these domestic 
sources, some variables for which there are no sufficient data from the domestic sources are collected from external sources, especially from IMF and WB databases.

\subsection{Model specification}

According to the third neo-classical growth model, output growth results from effective allocation of one or more of three factors: labor in terms of quantity and quality through population growth and education, increase in capital through saving and investment, and improvement in technology (Todaro, 1994: 86). The assumption of this model is that poor economies with lower values of capital and output tend to catch up with the initial rich ones. This model also assumes that population and technology as exogenously determined and production functions are assumed to satisfy the law of diminishing returns. Although the neo-classical growth model has its limitations in some aspects, it can be applied by some modification of population exogenous assumptions and is better for this study.

The standard neoclassical model of economic growth concerns rates on the Cobb-Douglas production function in the form of:

$$
Y_{t}=A_{t} K_{t}^{\partial} L_{t}^{\beta}------------------------------(3.1)
$$

Where: $\mathrm{Y}$ is total output, $\mathrm{K}$ denotes capital, $\mathrm{L}$ represents labor, $\mathrm{A}$ is total factor of productivity, $\partial$ is elasticity of output with respect to capital and $\beta$ is elasticity of output with respect to labour But, according to the objective of the study, labor can be considered as part of population (not as special productive force). Therefore, labor is replaced by total population and equation (1) can be written as:

$$
Y_{t}=A_{t} K_{t}^{\partial} P_{t}^{\beta}------------------------------(3.2)
$$

Furthermore, the effect of technology $\left(\mathrm{A}_{\mathrm{t}}\right)$ is divided into constant term $\beta_{0}$ and country specific deviation $\varepsilon$ (Imoughele et al., 2013).

$$
\ln Y_{t}=\beta_{0}+\alpha \ln K_{t}+\beta \ln P_{t}+\varepsilon_{t}-------------------- \text { (3.3) }
$$

Rather than taking the entire unexplained variable in the technology which is exogenously determined, including additional combination variables in the model that should be a proxy for technology is important because it makes the model more predictable and appropriate to know the accurate effects these variables on economic growth (Imoughele et al., 2013). Therefore, $\varepsilon_{t}=X_{t}+U_{t}$, the above equation can be rewritten as below when control variables are included;

$$
\ln Y_{t}=\beta_{0}+\alpha \ln K_{t}+\beta \ln P_{t}+\mu X_{t}+U_{t}------------------(3.4)
$$

Where $\mathrm{K}$ is total capital stock proxied by gross investment as \% of GDP and Pt is Total population proxy for population growth whereas $\mathrm{X}_{\mathrm{t}}$ is a vector of control variables namely inflation and trade openness.

$\mathrm{GDP}=\mathrm{F}$ (population, investment, inflation, trade openness)

Sinceall the variables under study were transformed into Log data so as avoid heteroscedasticity(Gujarati., 2004) and to show elasticity of the variables; the growth function of equation can be re-written as:-

$$
L N R G D P_{t}=\beta_{0}+\beta_{1} L N G C F_{t}+B_{3} L N P O P_{t}+B_{4} I N F L A T I O N_{t}+B_{6} L N T O_{t}+U_{t}-\text { (3.5) }
$$

Where, $\quad \mathbf{G D P}=$ real Gross Domestic Product

$$
\mathbf{P O P}=\text { Total population }
$$

$\mathbf{G C F}=$ capital stock accumulation proxied by Gross capital formation

$\mathbf{I N F}=$ Inflation proved by consumer price index 
$\mathbf{T O}=$ Trade openness which is the summation of Export + Import dived by GDP.

$\mathbf{U}=$ Disturbance term (factors that are not explained)

$\mathbf{t}=$ time period

\subsection{Estimation procedures}

\subsubsection{Unit Root Test}

The necessary condition to be addressed for testing unit root test is to check whether the variables enter in the regression are not order two (I.e. I(2)). Therefore, running any sort of regression analysis is impossible without testing for time series variables. So, the first step in this study is testing unit root before running regression analysis. The testing procedure for the ADF unit root test is specified as follows:

$$
X_{t}=\alpha+\delta t+\mu X_{t-1}+\sum_{i=1}^{\rho} \lambda \Delta X_{t-i}+\varepsilon_{t}
$$

Where is $\boldsymbol{X}_{\boldsymbol{t}}$ a time series variables which are mentioned above in this model at time $\mathrm{t}, \mathrm{t}$ is a time trend variable; $\Delta$ denotes the first difference operator; is the error term; $\rho$ is the optimal lag length of each variable chosen such that first-differenced terms make $\varepsilon_{t}$ a white noise. Thus, the ADF test the null hypothesis of no unit root (stationary) which is expressed as follows

$$
H_{0}: \mu=0 ; H_{1}: \mu \neq 0
$$

Regarding decision of unit root test, if the t value or t-statistic is more negative than the critical values, the null hypothesis (I.e. H0) is rejected and the conclusion is that the series is stationary. Conversely, if the t-statistic is less negative than the critical values, the null hypothesis is accepted and the conclusion is that the series is nonstationary. Failure to reject the null hypothesis of unit root test leads to take the test on the difference of the time series to come up out with stationary variable for analysis.

\subsubsection{The Autoregressive distributed lag Model (ARDL)}

There are numbers of advantages of using ARDL model also called 'Bound Testing Approach' instead of the conventional Engle-Granger two-step procedure (1987), Maximum likelihood methods of cointegration (Johansen, 1988) and Johansen and Juselius (1990).

First, the ARDL model is the more statistically significant approach to determine the cointegration relation in small samples as the case in this study (Pesaran et al., 2001; Narayan, 2004). A second advantage of the ARDL approach is that while other cointegration techniques require all of the regressors to be integrated of the same order; the ARDL approach can be applied whether the regressors are purely order zero [I(0)], purely order one [I(1)], or mixture of both. Third, with the ARDL approach it is possible to capture different optimum number of lengh for different variables. Finally, Appling the ARDL technique we can obtain unbiased and efficient estimators of the model (Narayan, 2004). Therefore, this approach becomes prevalent and appropriate for investigating the long-run relationship and extensively applied in empirical research in the recent years.

Hence, ARDL model can be specified as:

$$
\begin{aligned}
& \Delta L N R G D P_{t}=\beta_{0}+\beta_{1} L N P O P+\beta_{2} L N G C F_{t-1}+\beta_{3} L N C P I_{t-1}+\beta_{4} L N T O_{t-1}+\sum_{j=1}^{P} \alpha_{j} \Delta L N R G D P_{t-j}+ \\
& \sum_{j=1}^{q} \alpha_{j} \Delta L N P O P_{t-j}+\sum_{k=1}^{r} \alpha_{k} \Delta L N G C F_{t-k}+\sum_{l=1}^{s} \alpha_{l} \Delta L N C P I_{t-l}+ \\
& \sum_{m=1}^{v} \alpha_{m} \Delta L N T O_{t-m}+U_{t}
\end{aligned}
$$

- Where the symbol $\Delta$ is the first difference operator; $p, q, r, s$, and $v$ are the lag length with their 
respective variables and $U_{t}$ error term which is assumed to be serially uncorrelated.

○ $\beta_{1}, \beta_{2}, \beta_{3}, \beta_{4}$ indicates coefficients that measure long run elasticies between the variable whereas $\alpha_{i}, \alpha_{j}, \alpha_{k}, \alpha_{l}, \alpha_{m}$ indicates coefficients that measure short-run elasticities among the variable.

The first step involved in ARDL model is to test the null hypothesis of no cointegration relationship which is defined as $H_{O}=\beta_{1}=\beta_{2}=\beta_{3}=\beta_{4}=0$ against the alternative hypothesis of $H_{1} \neq \beta_{1} \neq \beta_{2} \neq \beta_{3} \neq \beta_{4} \neq 0$ of the existence of co integrating relationship between the variables. According to Pesaran et al. (2001), there are two sets of critical value bounds for all classifications of regressors' namely upper critical bound value and lower critical bound value. The critical values for I (1) series are referred to as upper bound critical values; while the critical values for I ( 0 ) series are referred to as lower bound critical values. If the calculated F statistic is greater than the upper bound critical values, we reject the null hypothesis of no long run relationship among the variables. If the calculated F statistic is less than the lower bound critical values, we can't reject the null hypothesis rather accept the null hypothesis of no co integration among the variables. However, if the calculated F statistic is between the upper and lower bound critical values, inference is inconclusive and we need to have knowledge on the order of integration of underling variables before we made conclusive inference (Pesaran et al., 2001).

Accordingly, with the existence of cointegration, the short run elasticities can also be manipulated through building the error correction of the series as stated the follows.

$$
\begin{aligned}
\Delta L N R G D P_{t}=\beta_{0} & +\sum_{j=1}^{P} \alpha_{j} \Delta L N R G D P_{t-j}+\sum_{j=1}^{q} \alpha_{j} \Delta L N P O P_{t-j}+\sum_{k=1}^{r} \alpha_{k} \Delta L N G C F_{t-k}+\sum_{l=1}^{s} \alpha_{l} \Delta L N C P I_{t-l} \\
& +\sum_{m=1}^{v} \alpha_{m} \Delta L N T O_{t-m}+U_{t}
\end{aligned}
$$

Here all variables are as previously defined. The order of the lags in the ARDL Model is selected by either the Akaike Information criterion (AIC) or the Schwarz Bayesian criterion (SBC) automatically, before the selected model is estimated by ARDL model.

\begin{tabular}{|c|c|c|c|}
\hline Variable & Description & Variable name & Expected sign \\
\hline Real GDP & Real gross domestic product & rGDP & \\
\hline Population & Total population & Pop & -ve/+ve \\
\hline Gross capital formation & $\begin{array}{l}\text { Capital stock proved to gross capital } \\
\text { formation }\end{array}$ & GCF & + ve \\
\hline Inflation & Inflation proved by consumer price index & Inf & -ve \\
\hline openness & $\begin{array}{l}\text { Trade openness is the summation export } \\
\text { and import dived by GDP }\end{array}$ & To & + ve \\
\hline
\end{tabular}

Table 1 variable description and hypothesis

\section{RESULTS AND DISCUSIONS}

\subsection{Results of unit root test}

Stationerity of the data is the prerequisite for the next steps in time series analysis. Therefore, accordingly by using ADF test method. When we check stationarity of variable by ADF, all variables is non-stationary at level so they are differenced. From the augmented dickey fuller test, the variables are integrated at different order and none of the variables are integrated of order two. 
Table 2: ADF stationary test

\begin{tabular}{|c|c|c|c|c|c|c|c|c|}
\hline \multirow{3}{*}{ Variables } & \multicolumn{4}{|c|}{ ADF test at level } & \multicolumn{4}{|c|}{ ADF test at $1^{\text {st }}$ differenced } \\
\hline & \multirow[t]{2}{*}{ t-static } & \multicolumn{3}{|c|}{ Critical value } & \multirow[t]{2}{*}{ t-static } & \multicolumn{3}{|c|}{ Critical value } \\
\hline & & $1 \%$ & $5 \%$ & $10 \%$ & & $1 \%$ & $5 \%$ & $10 \%$ \\
\hline Ln RGDP & 3.71 & -3.63 & -2.95 & -2.61 & $-5.32 *$ & -3.64 & -2.955 & -2.61 \\
\hline Ln POP & -0.96 & -3.63 & -2.95 & -2.61 & $-5.61 *$ & -3.64 & -2.955 & -2.61 \\
\hline Ln GCF & 1.73 & -3.63 & -2.52 & -2.61 & $-7.16^{*}$ & -3.64 & -2.955 & -2.61 \\
\hline Ln CPI & 0.16 & -3.63 & -2.52 & -2.61 & $-5.81 *$ & -3.64 & -2.955 & -2.61 \\
\hline Ln TO & -0.95 & -3.63 & -2.52 & -2.61 & $-4.90 *$ & -3.64 & -2.955 & -2.61 \\
\hline
\end{tabular}

Source: Author's computation of E view 9.5 result, 2020

Notes: The sign of '*' represents the rejection of the null hypothesis of non-stationary at 1\% significant level respectively.

For the model, since all values of ADF test statistics (in absolute value) are greater than all critical values, the variables are non-stationary at this level. However, each series can pass the test at their first difference because the critical values of each series are greater than $\mathrm{ADF}$ test statistic at $1 \%, 5 \%$ and $10 \%$ in absolute value with significant $\mathrm{p}$-value. Therefore, we can reject the hypothesis because the data are stationary in this difference; that means any variable by itself is an I(1) time series

\subsection{Diagnostic test}

Before generalizing diagnostic test, it was prerequisite to conduct model specification problem, normality in the residuals and heteroscedasticity. One of the assumptions of CLRM (classical linear regression model) is the disturbance "Ui" are Homoscedasticity that is they all have the same variance $\left(\delta^{2}\right)$. If this is not the case indicating that it is varying from observation to observation, we have a situation of heteroscedasticity or non-constant variance in the presence of heteroscedasticity, the usual hypothesis testing routine is not reliable, raising the possibility of drawing miss leading conclusion of making a variable insignificant because it will make OLS estimates to have larger variance and wider confidence interval. Therefore, it's important to consider it (Gujarati, 2004).

The above table indicates that the long run ARDL model estimated in this study passes all the diagnostic tests. To be sure whether the model fulfills the null-hypothesis or not, we can check residual appropriateness in three different ways. As the criteria, if the variables have relationship, the residual (a) shouldn't be serially correlated (non-auto correlated), (b) should not be heteroscedastic and (c) should be normally distributed, d) model is correctly specified; otherwise the model can violate the assumption of null hypothesis.

Table depicts that the above three criteria are fulfilled because all of them are insignificant since p-values for three obs. ${ }^{*}{ }^{2}$ s and Jaque-Bera statistic are greater than 5\%; so that we should reject the null-hypothesis. The implication is that there are stable relationships between the variables in the long-run. 
Table 3: Long run ARDL Diagnostic Tests

\begin{tabular}{|l|l|l|l|l|}
\hline Tests & \multicolumn{2}{|l|}{ LM-version } & \multicolumn{2}{l|}{-version } \\
\cline { 2 - 5 } & Statistic & P-value & Statistic & P-value \\
\hline $\begin{array}{l}\text { A:Serial Correlation: Breusch-Godfrey } \\
\text { serial correlation LM test }\end{array}$ & $\chi 2(2)=4.2477$ & 0.1895 & $F(2, \quad 27)=$ & 0.1731 \\
\hline $\begin{array}{l}\text { Heteroskedasticity: Breusch-Godfrey } \\
\text { test }\end{array}$ & $\chi 2(10)=8.3604$ & 0.7841 & $F(10, \quad 29)=$ & 0.4311 \\
\hline Normality: Jarque-Bera test & & & 0.548321 & \\
\hline Functional Form: Ramsey RESET test & $\chi 2(1)=.281947$ & 0.8844 & $F(1,31)=.1294$ & 0.8844 \\
\hline
\end{tabular}

Source: Author's computation of E view 9.5 result, 2020

\section{Test of Parameter Stability}

The stability of the model for long run and short run relationship is detected by usingthe cumulative sum of recursive residuals (CUSUM) which helps as to show if coefficient of the parameters is changing systematically and the cumulative sum of squares ofrecursive residuals (CUSUMSQ) tests which is useful to indicate if the coefficient of regression is changing suddenly. Accordingly, if the blue line cross redline which is critical line and never returns back between two critical line, we accept the null hypothesis of the parameter instability whereas thecumulative sum goes inside the area (can returns back) between the two critical lines, then there is parameter stability in the short run and long run.

Figure 1: Plot of Cumulative Sum of Recursive Residuals (i)

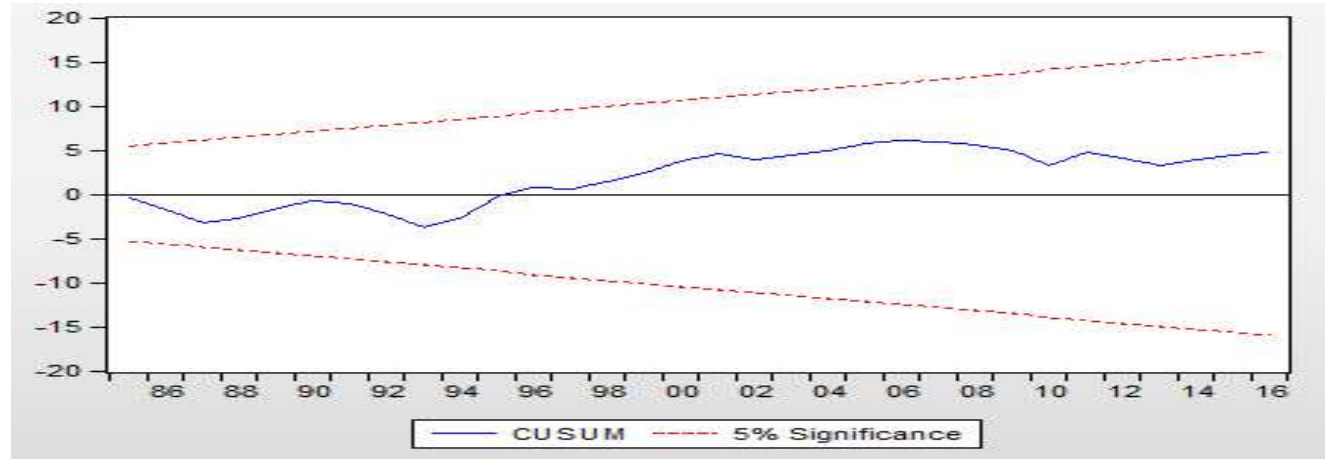

Figure 2: Plot of Cumulative Sum of Squares of Recursive Residuals (ii)

\subsection{Long Run ARDL Bounds Tests for Co-integration}

Since we determined the stationary nature of the variables, the next task in the bounds test approach of cointegration is estimating the ARDL model specified in equation (chapter 3) using the appropriate lag-length selection criterion. According to Pesaran and Shine (1999), as cited in Narayan (2004) for the annual data are recommended to choose a maximum of two lag lengths for small data because when the lag length increases the observation fail to show the appropriate long run relationship among variables because to show the long run relationship the number observation must be greater than 30 .

As we discussed so far, the F-test through the Wald-test (bound test) is performed to check the joint significance of the coefficients specified in equation (ARDL equation chapter 3 ). The Wald test is conducted by 
Journal of Economics and Sustainable Development

ISSN 2222-1700 (Paper) ISSN 2222-2855 (Online)

imposing restrictions on the estimated long-run coefficients of POP, GCF, CPI, and TO. The computed F-statistic value is compared with the lower bound and bound critical values provided by Pesaran et al. (2001) and Narayan (2004)

Table 4: bound test to cointegration

\begin{tabular}{llc}
\hline Lag & F statistics & Decision \\
\hline 1 & 6.04484 & Co integration \\
\hline Significance level & Lower bound & Upper bound \\
$10 \%$ & 2.45 & 3.52 \\
$5 \%$ & 2.86 & 4.01 \\
$2.5 \%$ & 3.25 & 4.40 \\
$1 \%$ & 3.74 & 5.06 \\
\hline
\end{tabular}

Source; own computation from EViews 9.5 result, 2020

From the above table calculated F statistics (6.044841) is higher than both the Pesaran et al. (2001) and Narayan (2004) upper bound critical values at 1\% level of significance. This implies that the null hypothesis of no long -run relationship is rejected; rather accept the alternative hypothesis (there is long-run relationship) based on critical values at $1 \%$ level of significance. Therefore, there is cointegration relationship among the variables in long run.

\subsection{Long Run ARDL Model Estimation}

After confirming the existence of long-run co-integration relationship among the variables, the next step is running the appropriate ARDL model to find out the long run coefficients, which is reported in table below.

Table 5: Long Run Coefficients co integrating equation

\begin{tabular}{lllll}
\hline Variable & Coefficient & Stan.error & t-statistics & Probabilities \\
\hline LNPOP & 0.403949 & 0.476434 & 2.847859 & 0.028 \\
LNTO & 0.162561 & 0.147305 & 1.105367 & 0.2780 \\
LNGCF & 0.490158 & 0.136299 & 3.596198 & 0.0011 \\
LNCPI & 0.779140 & 0.261877 & 2.975211 & 0.0055 \\
C & 11.146541 & 8.022849 & 1.389349 & 0.1743 \\
\hline
\end{tabular}

Source; own computation from EViews 9.5, 2020

Note: the sign $* * *$ and $* * *$ indicate that the variables are significant at the level of $1 \%, 5 \%$ and $10 \%$ respectively.

The result of the above table indicates that all the variables except CPI entered in the regression have the expected signs regardless of their significance level. As expected from economic theory, a population growth has positive impact and significantly affects GDP in Ethiopia. The long run responsiveness of growth domestic product (GDP) to the change in the total population is 0.40395 . This coefficient shows that assuming other things held constant, a percentage change in population size would increase growth domestic product by on average 0.40395 percent in the long run. The justification for positive impact represent that economy can adjust in the long run and absorb existing people as labor force and that the burden of population can be avoided so that people can play as active actor of economic development of the country.

The responsiveness of GDP toward the change growth capital formation (investment) is 0.49016 which is 
statistical significant to affect the economic growth. The coefficient reveals $1 \%$ increase in growth capital formation leads increase GDP by 0.49016 in the country economy. The positive responsiveness of this relationship leads high employment creation, higher income level which followed to higher aggregate demand of goods and services. Aggregate demand automatically increases because of expanded investment and employment. Therefore finally, the economy experienced by increased GDP.

The other significant determinant of GDP is inflation (consumer price index). The responsiveness of GDP to the change in inflation is 0.77914 . Meaning that $1 \%$ increase in inflation leads GDP to increase by 0.77914 . A rise in the inflation since it have a positive response to the increases in Real GDP, in turn lead to increase in the country money supply, investment, national income and aggregate demand. However, the long run responsiveness of GDP to the change in trade openness (export + import) has positive relationship but insignificantly affect Ethiopia's GDP.

\subsection{Short Run Error Correction Model}

After the acceptance of long-run coefficients of the GDP equation, the short-run ECM model is estimated. The error correction term (ECM), as we discussed in chapter three, indicates the speed of adjustment to restore equilibrium in the dynamic model. It is one lagged period residual obtained from the estimated dynamic long run model. The coefficient of the error correction term indicates how quickly variables converge to equilibrium. Moreover, it should have a negative sign and statistically significant at a standard significant level (i.e. $\mathrm{p}$-value should be less than 0.05)

Table 4.5 short run error correction

\begin{tabular}{lllll}
\hline Variable & Coefficient & Standard error & t-statistics & Prob. \\
\hline D(LNPOP) & -1.7615 & 1.30938 & -2.3453 & 0.0180 \\
D(LNGCF) & 0.10798 & 0.0502 & 2.1508 & 0.2270 \\
D(LNCPI) & 0.4410 & 0.08255 & 5.34226 & 0.0391 \\
D(LNCPI(-1)) & 0.29022 & 0.079995 & 3.62798 & 0.000 \\
D(LNTO) & 0.0358 & 0.02907 & 1.2318 & 0.0010 \\
ECM(-1) & -0.220287 & 0.07214 & -3.05306 & 0.0045 \\
\hline
\end{tabular}

Source; own computation from Eview 9.5 result, 2020

Note: the sign $* * *$ and $* * *$ indicate that the variables are significant at the level of $1 \%, 5 \%$ and $10 \%$ respectively. $\mathrm{R}^{2}=0.733275 \quad$ ADJ $\mathrm{R}^{2}=0.666593 \quad$ F-STA $=10.997(0.0000) \quad$ DW STAT $=2.0407$

The coefficient of determination (R-squared) is high explaining that about $73 \%$ of variation in the GDP is attributed to variations in the explanatory variables in the model. In addition, the DW statistic does not suggest autocorrelation and the F-statistic is quite robust. The large number F-statistic implies overall jointly significant the independent variables in the model. Furthermore, the results also reveal that CPI including one year lag and trade liberalization measured by trade openness are positive and significant determinant of the GDP in Ethiopia in the short run.

Surprisingly, population size growth is significant and negatively affecting economic growth in Ethiopia at least in the short run. This result is agrees with the study's expectation which stated that population grow has a negative effect on economic growth of Ethiopia. This is based on the fact that as the population increases, the 
young population (below 15 years) also increases along with it and as such takes time for them to mature to become economically active. At this point in time they are entirely dependent on the active labour force for their livelihood. This is because at this stage they do not produce anything to add up to GDP growth but rather consume what already exist. The empirical result is consistent with Razin and Sadka (1995) who reported a negative relationship between population growth and economic growth. The empirical result again corroborates with Dao (2012) who revealed that population has negative impact on economic growth.

If the variables are cointegrated, their dynamic relationship can be specified by an error correction representation in which an error correction term (ECT) computed from the long-run equation must be incorporated in order to capture both the short-run and long-run relationships (Engle and Granger, 1991). The error correction coefficient, estimated at -0.22 is highly significant, has the correct negative sign, and implies a very high speed of adjustment to equilibrium. Moreover, the coefficient of the error term implies that the deviation from long run equilibrium level of GDP in the current period is corrected by $22 \%$ in the next period to bring back equilibrium when there is a shock to a steady state relationship.

\section{Conclusion and policy implication}

The general objective of the paper was stressed to assess the determinant and over all issues of rapid population growth and its impact on economic growth in Ethiopia. The variables used in model were, population, consumer price index, gross investment proxied by gross capital formation and trade openness as explanatory variables and real GDP proxy for economic growth used as dependent variable. To check stationarity properties of the data augmented duller unit root test was used and the result indicates all the variables are non-stationary at level and become stationary at first difference. Regarding to cointegration test, ARDL bound test used to test the existence of long-run association among the variables and the result confirmed that there is long run relationship among real GDP and explanatory variables. The empirical result obtained from ARDL Model revealed that population issue is very controversial because although it has negative impact in the short run, implication is positive in the long run as we have seen. The short run implication explains that large number of economically inactive people with high growth rate of population depresses the GDP growth of the country whereas economy can adjust in the long run and absorb existing people as labor force and that the burden of population can be avoided so that people can play as active actor of economic development of the country.

As obtained from the result, high rate of population growth has held per capita GDP of the country at low level in the short run. Therefore, government should reduce rapid population growth in the country through well conducted population policy that can address the main population growth impact through successfully accomplish of plans such as; expanding job opportunity, social service distribution, infrastructure facilities, proper utilization or mobilization of resource, protection of environment and reduction of rural- urban migration.

Moreover, Government should motivate participation of private and NGOs investment by creating better conducive environment for investment to expand more job opportunity, to increase production of good and services, to reduce dependence ratio and unemployment, increase per capital income and improving living standard of the society. 
Journal of Economics and Sustainable Development

ISSN 2222-1700 (Paper) ISSN 2222-2855 (Online)

\section{Bibliography}

Afzal, M., Farooq, M. S., Ahmad, H. K., Begum, I., \& Quddus, M. A. (2009). Relationship between school education and economic growth in Pakistan: ARDL bounds testing approach to cointegration. Pakistan Economic and Social Review, 39-60.

Barlow, Robin. (1994). “Population Growth and Economic Growth: Some More Correlations.” Population and Development Review 20(1): 153-165.

Barro, RobertJ. (1991). “Economic Growthin a Cross-section of Countries. ”QJE106(2): 407-443.

Befekadu.D and Birhanu, N, . (2000). Annual report on the Ethiopian Economy, Addis Ababa, Ethiopia.

Birdsall, Allen C. Kelley, and Steven W. Sinding,eds. (2003). .PopulationMatters:Demographic Change, Economic Growth, and Poverty in the Developing World. Oxford: OUP.

Bloom and Richard B. Freeman. (1986). "The Effects of Rapid Population Growth on Labor Supply and Employment in Developing Countries." Population and Development Review 12(3): 401-08.

Dao, M. Q. (2012). Population and economic growth in developing countries. International Journal of Academic Research in Business and Social Sciences, 2(1), 6-17.

EH, Tartiyus,. (2009). impact of population growth in economic growth Ethiopia.

Engle, R. F., \& Granger, C. W. (1991). Long-run economic relationships: Readings in cointegration. Oxford University Press. .

Engle, RF \& Granger, CWJ,. (1987). 'Co-integration and error correction: representation, estimation and testing', Econometrica, vol. 55, no. 2, pp. 251-276.

Ethiopian Economic Association(EEA), . (2000). Annual Report on the Ethiopian Economy, Addis Ababa, Ethiopia.

Goodfriend, Marvin and John McDermott. (1995). “Early Development,” AER 85 (March): 116-133.

Gujarati. (2004). Basic econometrics. McGraw-Hill Companies, 4th edition.

Imoughele, Lawrence, Ehikioya, Ismaila And Mohammed. (2013). Commercial Bank Credit Accessibility And Sectoral Output Performance in a Deregulated Financial Market Economy: Empirical Evidence From Nigeria, . Journal of Finance and Bank Management, Vol. .

Johansen, S. . (1988). Statistical Analysis of Cointegration Vectors. Journal of Economic Dynamics and Control, 12(2/3), pp. 231-254. DOI: 10.1016/01651889(88)90041-3.

Johansen, S., and Jtiselius, K. . (1990). Maximum Likelihood Estimation and Inference on Cointegration - with Applications to the Demand for Money. Oxford Bulletin of Economics and Statistics, 52(2), pp. 169-210.

Malthus, R. (1798). Essay on the Principle of Population.

Mankiw, N. Gregory, David Romer, and David N. Weil. (1992). “A Contribution to the Empirics of Economic Growth." QJE 107(2): 407-437.

Nayaran, K. . (2004). Reformulating Critical Values for the Bounds F-statistics Approach to Cointegration: An Application to the Tourism Demand Model for Fiji. Discussion Papers No: 02, Monash University, Victoria, Australia.

Pesaran, H. M., \& Shin, Y. (1995). Autoregressive Distributed Lag Modeling Approach to Cointegration Analysis. Working Paper, No. 95/14. Department of Economics, University of Cambridge, DAE.

Pesaran, H., and Shin, Y. . (1999). An Autoregressive Distributed Lag Modeling Approach to Co-integration 
Analysis. UK: Cambridge University Press.

Pesaran, M., Shin, Y., \& Smith, R. . (2001). Bounds Testing Approaches to the Analysis of Level Relationships. Journal of Applied Econometrics, 16, 289-326. https://doi.org/10.1002/jae.616.

Razin, Assaf and Efraim Sadka. (1995). Population Economics. Cambridge, MA: MIT Press.

Simon, Julian L. . (1979). “The Case for More People.” American Demographics 1(1): 26-30.

Todaro Michael . (1994). Economic Development, New York, London,.

U.N. Population Division. (2002). Future Population Growth to Be Concentrated in Urban Areas of World. New York: U.N. 